(6) OPEN ACCESS

For numbered affiliations see end of article.

\section{Correspondence to} Professor lan Needleman, Unit of Periodontology, UCL Eastman Dental Institute, 256 Gray's Inn Road, London WC1X 8LD, UK ;

i.needleman@ucl.ac.uk

Accepted 13 August 2014 Published Online First 28 September 2014

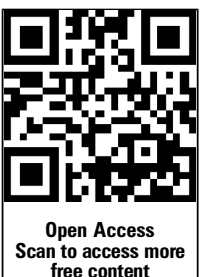

\section{CrossMark}

To cite: Needleman I, Ashley $\mathrm{P}$, Fine $\mathrm{P}$, et al. Br J Sports Med 2015;49:3-6.

\title{
Oral health and elite sport performance
}

Ian Needleman, ${ }^{1}$ Paul Ashley, ${ }^{1}$ Peter Fine, ${ }^{1}$ Fares Haddad, ${ }^{2}$ Mike Loosemore, ${ }^{2}$ Akbar de Medici, ${ }^{2}$ Nikos Donos, ${ }^{1}$ Tim Newton, ${ }^{3}$ Ken van Someren, ${ }^{4}$ Rebecca Moazzez, ${ }^{3}$ Rod Jaques, ${ }^{5,6}$ Glenn Hunter, ${ }^{5}$ Karim Khan, ${ }^{7,8}$ Mark Shimmin, ${ }^{9}$ John Brewer, ${ }^{10}$ Lyndon Meehan, ${ }^{11}$ Steve Mills, ${ }^{12}$ Stephen Porter ${ }^{1}$

\section{ABSTRACT}

While the research base is limited, studies have consistently reported poor oral health in elite athletes since the first report from the 1968 Olympic Games. The finding is consistent both across selected samples attending dental clinics at major competitions and more representative sampling of teams and has led to calls from the International Olympic Committee for more accurate data on oral health. Poor oral health is an important issue directly as it can cause pain, negative effects on appearance and psychosocial effects on confidence and quality of life and may have long-term consequences for treatment burden. Self-reported evidence also suggests an impact on training and performance of athletes. There are many potential challenges to the oral health of athletes including nutritional, oral dehydration, exercise-induced immune suppression, lack of awareness, negative health behaviours and lack of prioritisation. However, in theory, oral diseases are preventable by simple interventions with good evidence of efficacy. The consensus statement aims to raise awareness of the issues of oral health in elite sport and recommends strategies for prevention and health promotion in addition to future research strategies.

\section{INTRODUCTION}

Oral health is an integral part of general health and well-being and a basic human right ${ }^{1}$

A consistent finding in published studies is that oral health of elite athletes is poor (both selected samples attending dental clinics or more representative evaluations of teams). This is a striking statement considering the preventable nature of oral diseases and their potential for impact on health, well-being and performance of otherwise healthy, fit and highly prepared athletes. Dental consultations at the London 2012 Summer Olympic Games comprised $30 \%$ of all medical visits (second only to musculoskeletal), ${ }^{2}$ highlighting the burden of oral healthcare on facilities during major competitions. This demand has increased over successive games. ${ }^{3}$

\section{CALL TO ACTION}

Our purpose with this consensus statement is a call to action regarding oral health in sport since there is no evidence of an improving situation. As background, this paper will first summarise the key issues; what we know about oral health in elite sport, the impact of oral health on performance, how oral health might affect performance, why athletes have poor oral health and evidence-based oral health promotion and disease prevention. It will then conclude with recommendations to guide the improvement of oral health in elite athletes. Methods: this consensus statement is informed by a systematic review and subsequent discussion by participants of the symposium, Oral Health and Performance in Sport-Learning from London 2012, 4 April 2013, UCL, London. Since several articles have been written about orofacial trauma previously, the focus of this statement is concerned with oral health.

\section{WHAT DO WE KNOW ABOUT ORAL HEALTH IN ELITE SPORT?}

We conducted a detailed systematic review based on the focused question: What is the oral health of athletes and what is the effect of oral health on athletic training and performance? ${ }^{4}$ We searched MEDLINE, EMBASE, EBSCO SPORTDiscus and OpenGrey up to October 2013 with no language restrictions. Duplicate screening, eligibility assessment, data abstraction and methodological quality were conducted of observational studies. Of 9858 potentially relevant citations, 39 studies were eligible for review. We limited the review to studies on elite or professional sport participants. The included studies represented a wide range of sports, particularly Olympic, with Europe being the most frequent location for research (38\% studies). The studies represented true epidemiological research as well as reports of service utilisation in polyclinics. In view of differences in methodology, data were summarised by ranges rather than attempting meta-analysis.

Overall, oral health was consistently poor across these studies, especially considering the young age of the participants. Dental caries, periodontal disease, dental erosion and pericoronitis (infections around wisdom teeth)/impacted third molars were widely reported. The range of proportion of athletes affected by these conditions were dental caries $15-75 \%$, moderate-to-severe periodontitis up to $15 \%$, dental erosion $36-85 \%$ and pericoronitis/ impacted third molars 5-39\%. Dental trauma was reported by $14-57 \%$ of athletes in at-risk sports. Disease incidence was generally not clearly differentiated by socioeconomic status, however, poor oral health appears to affect athletes both from developing and developed countries. There are however, important limitations to the data: (1) The methodological strength of evidence was generally low. (2) The data include both studies where the sampling of athletes may not be representative (eg, attendance at dental clinics) as well as those investigating whole teams. However, poor oral 
health was common to both sets of studies. (3) The number of studies is relatively low. In summary, within the limitations described, the available evidence suggests

1. Poor oral health is common in elite or professional athletes;

2. The oral health of elite athletes is similar to non-athlete disadvantaged populations.

\section{WHAT DO WE KNOW ABOUT ORAL HEALTH AND IMPACT ON ELITE SPORT PERFORMANCE?}

The systematic review also searched for evidence for an impact of oral health on performance. Four studies reported relevant data which were all athlete self-reported measures. Some studies included athletes attending dental clinics and others assessment of complete teams. The proportion of athletes reporting a negative impact of their oral health included 33-66\% following trauma, $28-40 \%$ being bothered by their oral health or with an impact on their quality of life and $5-18 \%$ with an effect on performance. There were no data on the effect of oral health on time loss or impact on training quality. In summary, although the tools used to measure impact on performance and quality of life appeared to lack sensitivity and the samples are mostly from those attending for dental care, a sizeable proportion of athletes appear to report an impact on their well-being, training or performance.

\section{HOW MIGHT ORAL HEALTH AFFECT PERFORMANCE?}

Oral health is one of the determinants of life quality. ${ }^{5}$ There is a wealth of literature demonstrating impacts of oral diseases on the quality of life including caries, ${ }^{6}$ periodontal disease ${ }^{7}$ and pericoronitis. ${ }^{8}$ With clear psychosocial impacts of oral health, it would be surprising if training and performance were not affected in those athletes with poor oral health. Furthermore, subtle effects on training and performance could conceivably be highly important in an environment in which the 'aggregation of marginal gains' is critical. Impacts on performance from oral diseases could arise from pain ${ }^{10}$ increased systemic inflammation ${ }^{11}$ and impaired confidence and socialisation. ${ }^{5}$ In summary, poor oral health could affect performance directly though pain arising from disease conditions but also more subtly from effects such as increased systemic inflammation and psychosocial impacts that may be less evident to athletes themselves.

\section{WHY MIGHT ATHLETES HAVE POOR ORAL HEALTH?}

There are many challenges to oral health in athletes. These include proximal factors close to the athlete and distal or more downstream factors.

\section{NUTRITION}

Nutritional intake, including usual diet, sports drinks and supplements is a major determinant of oral health, including dental caries, periodontal disease and dental erosion. Training and performance are often supported by carbohydrate-containing sports drinks and gels, ${ }^{12}$ which are taken frequently during activity. ${ }^{13}$ These drinks include energy drinks (normally with a $\mathrm{CHO}$ concentration of $>10 \%)$, isotonic sports drinks (4-8\% CHO) and hypotonic drinks (normally around $2 \% \mathrm{CHO}$ or less).

Dietary carbohydrate intake is one of the most wellcharacterised causative factors for dental caries ${ }^{14}$ and acidic foodstuffs and beverages are the main factors causing erosion. ${ }^{10}{ }^{15} \mathrm{~A}$ relationship between dental caries and frequency of sports drink intake has been reported in children, ${ }^{16}$ but few studies have examined this relationship in the elite athlete population. The proinflammatory effects of a high carbohydrate intake might also increase risk of periodontal disease. ${ }^{17}{ }^{18}$ Clearly, sports supplements are only part of nutrition in athletes that might affect oral health.

In several sports body weight, composition and aesthetics are crucial factors to the athlete, ${ }^{19-21}$ increasing the risk of eating disorders. It would seem appropriate that the early detection of eating disorders could prevent further detrimental effects both physically and mentally for patient. It has been shown that the elite athlete is more susceptible to eating disorders than the average member of society. The need to particularly reduce weight for example in boxing, horse riding, gymnastics and long-distance running can lead to eating disorders being prevalent. ${ }^{22}$ There is a role for the general dental practitioner and the sports dentist in particular to detect signs and symptoms of tooth erosion as a result of eating disorders. ${ }^{23}{ }^{24}$ It is therefore critical that elite athletes are screened for not only dental disease but what can be the first/earliest signs of eating disorders that manifest themselves in the oral cavity.

\section{HOST REGULATION}

Dehydration and local drying of the mouth during sporting activity might increase the impact of carbohydrates on caries and acidic drinks on erosion by reducing salivary flow or amount and therefore impairing the protective properties of saliva. $^{25}$ These properties include non-specific and specific antimicrobial activity (also important in protection against periodontal diseases) and re-mineralising effects of saliva. ${ }^{26}$ Immunoinflammatory protection against the microbial challenge of dental caries and periodontal disease could also be compromised by exercise-induced immune suppression. ${ }^{27}$

\section{HEALTH BEHAVIOURS, KNOWLEDGE AND ENVIRONMENT}

Health behaviours, health beliefs, oral health literacy, access to preventive programmes and prioritisation of time are all recognised as important determinants of oral health. ${ }^{28}$ Little is known about these factors in elite sport although awareness of risk of oral disease appears low ${ }^{13}$ and less than half of athletes in one sample attended for regular oral health assessments. ${ }^{10}$ However, regular attendance for dental examinations does not necessarily predict better oral health. ${ }^{29} 30$ Traditional models of dental clinic care and their remuneration focus on treatment rather than on preventing disease or promoting health. ${ }^{31-34}$ Therefore, athletes may still find difficulty in accessing preventive advice even where organised dental care is available. Furthermore, it would be simplistic to consider the athlete in isolation. Rather, the oral health of an individual athlete is very likely to be influenced or even dependent on the surrounding network of peers, support staff and organisations ${ }^{35} 36$ In summary, athletes are exposed to a number of challenges in maintaining good oral health including proximal factors directly under the control of the individual and more downstream, distal factors related to the local environment and support network.

\section{PROMOTION OF ORAL HEALTH, PREVENTION OF ORAL DISEASES AND MITIGATION OF RISK}

Oral diseases are preventable. ${ }^{37}$ Simple interventions may have a dramatic impact on oral health (summarised in table 1) including use of high strength fluoride toothpastes, other topical fluoride preparations, behavioural change related to diet and oral hygiene (effective dental plaque removal) and pattern of use of acidic drinks, for example, sports drinks. Early identification of pericoronitis and extraction of third molars if recurrent is also important. While not a focus of this statement, use of custommade mouthguards is important for participation in sports at risk of trauma. A further strategy to consider is mitigation of 
Table 1 Types of preventive and risk mitigation interventions for dental caries, periodontal disease, dental erosion and pericoronitis

\begin{tabular}{|c|c|}
\hline Condition & Intervention \\
\hline All conditions & $\begin{array}{l}\text { Health promotion, education and behaviour change: } \\
\text { multilevel approach including individual (athlete), local } \\
\text { (medical, dental and performance support team) and high } \\
\text { level (national/international sport organisations) }\end{array}$ \\
\hline Dental caries & $\begin{array}{l}\text { Dietary: when feasible, reduced frequency and amount of } \\
\text { carbohydrate intake. Matching sports drink to purpose, for } \\
\text { example, for hydration, hypotonic drink or water } \\
\text { Fluoride: for example, toothpaste containing at least } \\
1400 \text { ppm fluoride and preferably } 5000 \text { ppm } \\
\text { Oral hygiene: effective daily dental plaque removal } \\
\text { (toothbrushing and interdental cleaning) }\end{array}$ \\
\hline $\begin{array}{l}\text { Periodontal } \\
\text { disease }\end{array}$ & $\begin{array}{l}\text { Oral hygiene: behaviour change to achieve effective daily } \\
\text { dental plaque removal (toothbrushing and interdental } \\
\text { cleaning) } \\
\text { Assessment: early detection and treatment (secondary } \\
\text { prevention) } \\
\text { Risk factor reduction: tobacco use cessation }\end{array}$ \\
\hline Dental erosion & $\begin{array}{l}\text { Dietary: reduced frequency of acidic food/beverage intake } \\
\text { Sports drinks: where feasible; reduced frequency, avoiding } \\
\text { prolonged retention in mouth, using straw to drink }\end{array}$ \\
\hline Pericoronitis & $\begin{array}{l}\text { Oral hygiene: careful plaque removal around impacted third } \\
\text { molar } \\
\text { Extraction: extraction of third molar after no more than two } \\
\text { episodes of pericoronitis }\end{array}$ \\
\hline
\end{tabular}

risk. Since some risk factors may be difficult to reduce at times, for example frequency of carbohydrate intake during training, interventions which reduce harm might be helpful. For instance modified sports drinks have been reported. ${ }^{38} 39$ A brief summary of types of interventions is summarised in table 1 .

However, many of these interventions rely on or are affected by health behaviours which are notoriously difficult to change. ${ }^{40}$ Furthermore, as discussed above, the expression of oral health in an individual athlete should be considered the product of a matrix of factors, including more downstream determinants including their local environment and broader sporting context. Unfortunately, there are no studies in the literature that we are aware of that have reported on the effect of oral disease prevention or health promotion strategies in athletes.

A template has been developed by a recent IOC consensus statement regarding the prevention of non-communicable disease. ${ }^{40}$ Although not directed specifically at elite athletes, this guidance focuses on simple interventions that include a focus on behavioural change and which are designed with an understanding of individual preferences but with engagement and participation across relevant networks. Embedding oral health within such an approach would seem a realistic strategy to achieve both sustained change and mutual benefits for overall health, wellbeing and performance. ${ }^{41-43}$

\section{SUMMARY AND RECOMMENDATIONS REGARDING ORAL HEALTH IN ELITE ATHLETES}

1. Oral health: Poor oral health is common in elite athletes. Oral health is a basic right of athletes but has consistently been shown to be poor with a high treatment need. Dental caries, dental erosion, periodontal disease and pericoronitis (infection around impacted teeth) are the principal oral health conditions affecting athletes. Dental trauma in 'at-risk' sports is also recognised. The effect of poor oral health on athletes may have both short-term and long-term consequences. In the short-term, poor oral health can cause pain and distress, difficulties in eating and sleeping, reduced quality of life and impact on performance (see below). The long-term consequences include increased risk of tooth loss, increased treatment need and resulting functional and psychological impairments.

2. Causes of poor oral health: There are many challenges to the oral health of elite athletes, some of which act at the level of the athlete and others within the peer, community and sport organisational level. These issues include nutritional challenges from frequent carbohydrate intake and acidic sports drinks, impairment of host responses due to dehydration, mouth drying and intensive training, poor health behaviours and oral health literacy and lack of effective health promotion/preventive support.

3. Impact on performance: Emerging athlete self-reported evidence suggests that poor oral health negatively affects the training and performance of athletes. The mechanisms behind this effect might include pain, reduced well-being and quality of life and increased systemic inflammation.

4. Improving and maintaining the oral health of athletes: Oral diseases are preventable with well-characterised interventions at low cost. Some interventions are more dependent on behavioural change and adherence to care than others. To achieve a sustained effect, oral health should be embedded within other aspects of health promotion taking into account the structural issues and inter-relationship of athletes within their sport and peer networks. Such an approach could in addition achieve mutual benefits for general health, well-being and performance. Regular assessments of oral health by a dental professional, especially preseason, will allow for personalisation of prevention plans and early treatment of any disease. National sport funders and policy organisations should take a lead in integrating such an approach. Mitigation of risk approaches should also be investigated as part of an oral health strategy.

5. Research and surveillance: The research base to inform sport and exercise medicine is limited in amount and quality. ${ }^{41}$ Priority research questions to address include careful epidemiological evaluations of representative samples of athletes to establish oral health needs across different sports, the determinants of oral health both of the individual and their environment and the impact and associated mechanisms of oral health on performance. The optimal preventive, health promotion and risk mitigation strategies within elite sport need to be assessed. Such a research strategy calls for the establishment of innovative networks using creative research designs with expertise across oral health, sport and exercise medicine and science, public engagement and sports governing and funding organisations.

\section{Author affiliations}

${ }^{1}$ UCL Eastman Dental Institute, London, UK

${ }^{2}$ UCL Institute for Sport Exercise and Health, London, UK

${ }^{3} \mathrm{KCL}$ Dental Institute, London, UK

${ }^{4}$ Human Performance Lab, GlaxoSmithKline, Brentford, UK

${ }^{5}$ English Institute of Sport, Bath, UK

${ }^{6}$ Faculty of Sport and Exercise Medicine, Edinburgh, UK

${ }^{7}$ School of Kinesiology, University of British Columbia, Vancouver, British Columbia, Canada

${ }^{8}$ Aspetar Orthopaedic and Sports Medicine Hospital, Doha, Qatar

${ }^{9}$ Dental Practice, Marlow, UK

${ }^{10}$ St Mary's University, Twickenham, School of Sport, Health \& Applied Science, UK

${ }^{11}$ Dental Practice, Cardiff, UK

${ }^{12}$ Past President, Academy for Sports Dentistry, Farmersville, Illinois, USA 
Correction notice This paper has been amended since it was published Online First. Karim Khan's second affiliation was omitted and this has been reinstated. Also, John Brewer's affiliation has been changed to St Mary's University Twickenham, School of Sport, Health \& Applied Science.

Contributors IN conceived and wrote the first draft of the consensus statement and is the guarantor. PA, PF, FH, ML, AdM, ND, TN, KvS, RM, RJ, GH, KK, MS, JB, LM, SM and SP participated in the consensus meeting and gave substantial contributions to critically revising the article for intellectual content.

\section{Competing interests None.}

Provenance and peer review Not commissioned; externally peer reviewed.

Open Access This is an Open Access article distributed in accordance with the Creative Commons Attribution Non Commercial (CC BY-NC 4.0) license, which permits others to distribute, remix, adapt, build upon this work non-commercially, and license their derivative works on different terms, provided the original work is properly cited and the use is non-commercial. See: http://creativecommons.org/ licenses/by-nc/4.0/

\section{REFERENCES}

1 World Health Organisation. The Liverpool Declaration. Promoting oral health in the 21st century. http://www.who.int/oral_health/events/liverpool_declaration/en/ (accessed 25 Apr 2014).

2 Vanhegan IS, Palmer-Green D, Soligard T, et al. The London 2012 Summer Olympic Games: an analysis of usage of the Olympic village polyclinic by competing athletes. Br J Sports Med 2013;47:415-19.

3 Piccininni PM, Fasel R. Sports dentistry and the olympic games. J Can Dent Assoc 2005;33:471-83

4 Ashley P, Cole E, Di lorio A, et al. Oral health of athletes and association with performance: a systematic review. Br J Sports Med 2015;49:14-19.

5 Locker D. Measuring oral health: a conceptual framework. Community Dent Health 1988;5:5-13.

6 Foster Page LA, Thomson WM. Caries prevalence, severity, and 3-year increment, and their impact upon New Zealand adolescents' oral-health-related quality of life. J Public Health Dent 2012;72:287-94.

7 Needleman I, McGrath C, Floyd P, et al. Impact of oral health on the life quality of periodontal patients. J Clin Periodontol 2004;31:454-7.

8 McNutt M, Partrick M, Shugars DA, et al. Impact of symptomatic pericoronitis on health-related quality of life. J Oral Maxillofac Surg 2008;66:2482-7.

9 Team Sky. 2010. http://www.teamsky.com/article/0,27290,17547_5792058,00.html (accessed 25 Apr 2014).

10 Needleman I, Ashley P, Petrie A, et al. Oral health and impact on performance of athletes participating in the London 2012 Olympic Games: a cross-sectional study. Br J Sports Med 2013;47:1054-8.

11 Loos BG, Tjoa S. Host-derived diagnostic markers for periodontitis: do they exist in gingival crevice fluid? Periodontol 2000 2005;39:53-72.

12 Lun V, Erdman KA, Fung TS, et al. Dietary supplementation practices in Canadian high-performance athletes. Int J Sport Nutr Exerc Metab 2012;22:31-7.

13 Bryant S, McLaughlin K, Morgaine K, et al. Elite athletes and oral health. Int J Sports Med 2011;32:720-4.

14 Moynihan PJ, Kelly SA. Effect on caries of restricting sugars intake: systematic review to inform WHO guidelines. J Dent Res 2014;93:8-18.

15 Lussi A, Jaeggi T, Zero D. The role of diet in the aetiology of dental erosion. Caries Res 2004;3(Suppl 1):34-44.

16 Kawashita Y, Fukuda H, Kawasaki K, et al. Pediatrician-recommended use of sports drinks and dental caries in 3-year-old children. Community Dent Health 2011;28:29-33.

17 Baumgartner $\mathrm{S}$, Imfeld $\mathrm{T}$, Schicht 0 , et al. The impact of the stone age diet on gingival conditions in the absence of oral hygiene. J Periodontol 2009;80:759-68.

18 Chapple ILC. Potential mechanisms underpinning the nutritional modulation of periodontal inflammation. J Am Dent Assoc 2009;140:178-84.

19 Ackland TR, Lohman TG, Sundgot-Borgen J, et al. Current status of body composition assessment in sport: review and position statement on behalf of the $\mathrm{Ad}$
Hoc Research Working Group on Body Composition Health and Performance, under the auspices of the I.O.C. Medical Commission. Sports Med 2012;42:227-49.

20 Sundgot-Borgen J, Garthe I. Elite athletes in aesthetic and Olympic weight-class sports and the challenge of body weight and body compositions. J Sports Sci 2011;29(Suppl 1):S101-14.

21 Sundgot-Borgen J, Meyer NL, Lohman TG, et al. How to minimise the health risks to athletes who compete in weight-sensitive sports review and position statement on behalf of the Ad Hoc Research Working Group on Body Composition, Health and Performance, under the auspices of the IOC Medical Commission. Br J Sports Med 2013;47:1012-22.

22 Sundgot-Borgen J, Torstveit MK. Prevalence of eating disorders in elite athletes is higher than in the general population. Clin J Sport Med 2004;14:25-32.

23 Walsh JME, Wheat ME, Freund K. Detection, evaluation, and treatment of eating disorders. J Gen Intern Med 2000;15:577-90.

24 Hermont AP, Pordeus IA, Paiva SM, et al. Eating disorder risk behavior and dental implications among adolescents. Int J Eat Disord 2013;46:677-83.

25 Mulic A, Tveit A, Songe $D$, et al. Dental erosive wear and salivary flow rate in physically active young adults. BMC Oral Health 2012;12:8.

26 Lussi A, Jaeggi T, Zero D. The role of diet in the aetiology of dental erosion. Caries Res 2004;38(Suppl 1):34-44.

27 Gleeson M. Immune function in sport and exercise. J App/ Physiol 2007;103:693-9.

28 Watt RG. Emerging theories into the social determinants of health: implications for oral health promotion. Community Dent Oral Epidemiol 2002;30: 241-7.

29 Hill KB, Chadwick B, Freeman R, et al. Adult Dental Health Survey 2009: relationships between dental attendance patterns, oral health behaviour and the current barriers to dental care. Br Dent J 2013;214:25-32.

30 Riley $\mathrm{P}$, Worthington HV, Clarkson JE, et al. Recall intervals for oral health in primary care patients. [Update of Cochrane Database Syst Rev 2007;(4):CD004346; PMID: 17943814]. Cochrane Database of Syst Rev 2013;12:CD004346.

31 Richards W. Prevention in practice. Br Dent J 2008;205:111.

32 Sbaraini $A$. What factors influence the provision of preventive care by general dental practitioners? Br Dent J 2012;212:E18.

33 Pearce $M$, Catleugh $M$. Are general dental practitioners providing best practice in prevention in everyday general practice? Prim Dent J 2013;2:38-43.

34 Yokoyama Y, Kakudate N, Sumida F, et al. Dentists practice patterns regarding caries prevention: results from a dental practice-based research network. BMJ Open 2013;3:e003227.

35 Steffen K, Soligard T, Engebretsen L. Health protection of the Olympic athlete. Br J Sports Med 2012;46:466-70.

36 Geidne S, Quennerstedt M, Eriksson C. The youth sports club as a health-promoting setting: an integrative review of research. Scand J Public Health 2013;41:269-83.

37 Public Health England. Delivering better oral health, an evidence-based toolkit for prevention, 3rd edition: 2014. www.gov.uk/government/uploads/system/uploads/ attachment_data/file/319471/DBOHv3JUNE2014.pdf

38 Ramalingam L, Messer LB, Reynolds EC. Adding casein phosphopeptide-amorphous calcium phosphate to sports drinks to eliminate in vitro erosion. Pediatr Dent 2005;27:61-7.

39 Attin T, Weiss $\mathrm{K}$, Becker $\mathrm{K}$, et al. Impact of modified acidic soft drinks on enamel erosion. Oral Dis 2005;11:7-12.

40 Matheson GO, Klügl M, Engebretsen L, et al. Prevention and management of non-communicable disease: the IOC consensus statement, Lausanne 2013. Br J Sports Med 2013;47:1003-11.

41 Ljungqvist $A$, Jenoure $P$, Engebretsen $L$, et al. The International Olympic Committee (IOC) Consensus Statement on periodic health evaluation of elite athletes. Int Sport Med J 2009;10:124-44.

42 Sheiham A, Watt RG. The common risk factor approach: a rational basis for promoting oral health. Community Dent Oral Epidemiol 2000;28: 399-406.

43 Watt RG. From victim blaming to upstream action: tackling the social determinants of oral health inequalities. Community Dent Oral Epidemiol 2007;35:1-11. 